\title{
Bloodstream infection reduction rate within the first month after heart and lung transplant with broader spectrum antimicrobial prophylaxis
}

Elena Seminari $^{1 *}$, Annalisa De Silvestri ${ }^{2}$, Angela Di Matteo ${ }^{1}$, Patrizia Cambieri ${ }^{3}$, Federica Meloni ${ }^{4}$, Barbara Cattadori ${ }^{5}$, Annalisa Turco ${ }^{6}$, Roberto Veronesi ${ }^{7}$, Carlo Pellegrini ${ }^{5}$, Stefano Pelenghi ${ }^{5}$ and Raffaele Bruno ${ }^{8}$

${ }^{1}$ Clinica di Malattie Infettive, Fondazione IRCCS Policlinico San Matteo, Pavia, Italy

${ }^{2} \mathrm{SC}$ Biometria e Statistica, Fondazione IRCCS Policlinico San Matteo, Pavia, Italy

${ }^{3} \mathrm{SC}$ Microbiologia e Virologia, Fondazione IRCCS Policlinico San Matteo, Pavia, Italy

${ }^{4}$ Pneumology Unit, Fondazione IRCCS Policlinico San Matteo, Pavia, Italy

${ }^{5}$ Cardiac Surgery Unit, Fondazione IRCCS Policlinico San Matteo, Pavia, Italy

${ }^{6}$ Cardiology, Fondazione IRCCS Policlinico San Matteo, Pavia, Italy

${ }^{7}$ Intensive Care Unit 2, Fondazione IRCCS Policlinico San Matteo, Pavia, Italy

${ }^{8}$ Department of Clinical, Surgical, Diagnostic, and Pediatric Sciences, University of Pavia and Clinica di Malattie Infettive, Fondazione IRCCS Policlinico San Matteo, Pavia, Italy

\begin{abstract}
Introduction: Bloodstream infections (BSIs) occur early in the post transplant period, the aim of this retrospective study was to evaluate whether a broather antimicrobial prophylaxis at transplant could be helpful in reducing BSI incidence.

Method: All BSI episodes occurring considered as early (until 30 days after transplant) or late events (from 31 days to 365 days after transplant) were recorded. Before October 1st, 2018, vancomycin was used as prophylaxis at transplant (period 1); after October 1st,2018 prophylaxis included vancomycin and piperacillin/tazobactam (period 2) or a targeted prophylaxis according to the colonization bacteria detected through rectal swab.

Results: One-hundred-fifteen patients received a SOT during the study (77 in period 1 and 38 in period 2),73 (63.5\%) heart recipients, and 42 (36.5\%) lung recipients. Fifty-four BSI episodes were recorded in 41 patients (36.7\%). Gram-negative bacteria were responsible for the majority of BSIs. Twenty-four patients died during the study timeframe (22\%) (type of SOT: 18 heart, 6 lung transplanted patients), having a BSI was a risk factor for death (HR 5.2; 95\% CI 2.1-12-5, p<0.001).

BSIs in the first 30 days after transplant accounted for $48 \%$ of all events. Overall BSI incidence rate was 1.15 per 100 patient/days in the first 30 days after transplant; 1.49 per 100 patient/days in period 1 and 0.58 per 100 patient/days in period 2 . The use of broader antimicrobial prophylaxis was associated with reduced BSI in period 2 compared to period 1 (HR 0.39; 95\%CI 0.16-0.93, p=0.035); CKD was associated with increased BSI risk (HR 2.45; 95\% CI 1.1-6, p=0.048). At multivariate analysis the risk of BSI still remained reduced in period 2 (HR 0.38; 95\%CI 0.14-1, p=0.05).
\end{abstract}

BSI incidence between 31 and 365 days after transplant was 0.15 per 100 patient/days, age remained associated to BSI in the late period at multivariate analysis.

Discussion: Broader antimicrobial prophylaxis at transplant is an option to reduce BSI incidence in the first month after transplant.

\section{Introduction}

Bloodstream infections (BSIs) represent a major complication of solid organ transplant (SOT) and are among the leading causes of morbidity and mortality in patients $[1,2]$. Overall, the rate of BSIs ranges from $8.6 \%$ to $26 \%$, depending on transplantation type [3]. Infections due to Gram-negative bacteria are nowadays the foremost cause of infection, their peak incidence occur early in post-transplant, typically within the first month $[1,4,5]$. Among these, Gram-negative carbapenem resistant (GNCR) strains associated bloodstream infection (BSIs) are a serious hazard for the patient's life [1,6,7], being rectal colonization with resistant strains associated with the occurrence of BSIs in the early post-transplant period [8-10]. There are no clear effective preventive measures to prevent GNCR infections after SOT in colonized patients. Selective decontamination with non-absorbable drugs, targeted antibiotic prophylaxis or preemptive treatment has been proposed [11,12] Due to a high incidence of (GNCR) BSIs in the early post-transplant period, a change in antimicrobial prophylaxis at

*Correspondence to: Elena Seminari, Clinica di Malattie Infettive, Fondazione IRCCS Policlinico San Matteo, 27100 Pavia, Italy, Tel: +39 0382 501543; E-mail: e.seminari@smatteo.pv.it

Key words: bloodstream infection, heart transplant, lung transplant, carbapenemase resistance, rectal colonization

Received: January 12, 2021; Accepted: January 19, 2021; Published: January 22, 2021 
transplant was implemented in October 2018 at our Centre. The aim of this study is to describe the microbiological etiology of BSIs within the first year after transplant in different SOTs (heart, lung) and to evaluate risk factors for BSIs and the possible role of broader antimicrobial prophylaxis at transplant on incidence of early and late BSIs.

\section{Materials and Methods}

\section{Study design and population}

A retrospective observational study was conducted at Fondazione IRCCS Policlinico San Matteo located in Pavia, Italy, a tertiary referral hospital which is part of a network of Centers with an active solid transplant program (heart, kidney, lung). All adult patients who underwent heart and lung SOT during the period from January $1^{\text {st }}$, 2015 to December 31 $1^{\text {st }}, 2020$ were included. All BSI episodes occurring within the first-year post-transplant were recorded. BSI episodes were considered as early (until 30 days after transplant) or late events (from 31days to 365 days after transplant). Data have been pseudoanonymized and stored in a password protected file. The study has been approved by local Ethical Review Board (prot 20180068992). Data on comorbidities such as diabetes, chronic kidney disease (CKD) and immunosuppressive regimens were collected for all patients. CD4+ and CD8+ lymphocytes cell counts were collected to evaluate the immunosuppressive state of the patients (within 30 days from BSI occurrence; otherwise, the lowest levels of both CD4 and CD8 $\mathrm{T}$ cells throughout the year was recorded). Recurrent BSI due to the same pathogen with overlapping mechanisms of resistance were not considered in the analysis.

\section{Immunosuppressive therapy}

Induction immunosuppressive therapy includes anti-thymocyte globulin and steroids in heart transplanted patients and steroids in lung transplanted patients; maintenance immunosuppressive treatments included steroids and mycophenolic acid/mycophenolate associated with a CNI (tacrolimus, ciclosporin) or mammalian target of rapamycin inhibitor (everolimus).

\section{Microbiological studies}

To enhance the diagnostic sensitivity, at least two blood samples from two different peripheral lines or from a central and a peripheral one, are withdrawn. 8-10 $\mathrm{ml}$ of the sample are collected in each of the BACTEC $^{\prime \prime}$ bottles set. The samples are ncubated in the BACTEC ${ }^{\text {mo }}$ 9240 or in an automated blood culture system (Becton, Dickinson and Company, Franklin Lakes, NJ, USA), according to the manufacturer's instructions within two hours from collection. The organisms are identified by Matrix-Assisted Laser Desorption Ionization time-offlight (MALDI-TOF) (BrukerDaltonics GmbH, Bremen, Germany) or by biochemical tests using Phoenix 100 (BD) automated system N-MIC/ID or P-MIC/ID panel GmbH, Bremen, Germany). The antimicrobial susceptibility is tested using Phoenix 100 (BD). A realtime PCR technology GeneXpert system (Cepheid, Sunnyvale, CA), performed according to the manufacturer's instructions, is used to detect methicillin/oxacillin resistance for blood cultures growing Gram-positive. A multiplex nested PCR FilmArray enables rapid (1h) and accurate detection of 24 pathogens (bacteria and yeasts) and 3 antibiotic resistance genes and rapid immunochromatographic tests is used for determination of resistance markers.

All surveillance rectal swabs are directly plated on chromID CARBA Agar to screen for the presence of carbapenemase-producing Enterobacterales, on chromID ESBL Agar (BioMérieux, Marcy-l'Étoile, France) to screen for the presence of ESBL-producing Enterobacterales and on chromID VRE agar to screen for the presence of Enterococci with resistance to glycopeptides. These selective chromogenic media allow the presumptive identification of Enterococcus, Proteeae (Proteus, Providencia, Morganella), and KESC group (Klebsiella, Enterobacter, Serratia, Citrobacter). Microorganisms are identified with the MALDI Biotyper 3.1 system based on Matrix-Assisted Laser Desorption Ionization time-of-flight (MALDI-TOF) (BrukerDaltonics, Bremen, Germany). Antibiotic susceptibility testing and minimum inhibitory concentrations (MICs) determinations are performed using the $\mathrm{BD}$ Phoenix 50 automated system (Becton, Dickinson and Company, Franklin Lakes, NJ, United States) and interpreted following the clinical breakpoints of the version 6.0 of the European Committee on Antimicrobial Susceptibility Testing with the broth microdiluition (Sensititre $^{\mathrm{tm}}$ DKMGN Thermo Scientific). The NG-Test Carba 5 (NG Biotech, Guipry, France) is used for the immunochromatographic detection of the five most widespread carbapenemase families KPC, NDM, VIM, IMP, and OXA-48-like enzymes.

\section{Antibiotic prophylaxis at transplant}

The transplant antibiotic prophylaxis policy was modified in the Center after October $1^{\text {st }}, 2018$, for heart and lung transplantation due to the observation of a high incidence of BSI during the first weeks after transplant. Before October 1st, 2018, vancomycin was used as antibiotic prophylaxis at transplant (period 1); after October $1^{\text {st }}, 2018$, bacterial prophylaxis included vancomycin and piperacillin/tazobactam for both heart and lung transplant. This scheme could be changed according to the colonizing bacteria detected through rectal swab performed before transplant (period 2). A targeted antimicrobial prophylaxis could be chosen for these colonized patients. Antimicrobial prophylaxis was continued for 48 hours.

\section{Statistical analysis}

Categorical variables were described by means of count and percentage, quantitative ones by means of median and interquartile rangeIQR $\left(75^{\circ}\right.$ percentile minus $25^{\circ}$ percentile). Chi-square test or Fisher's exact test were used in univariate analyses for categorical variables. A Kaplan-Mayer curve was fitted to estimate time to BSI and Cox proportional hazard regression in univariable and multivariable models has been fitted to evaluate the role of risk factors (type of prophylaxis, diabetes, $\mathrm{CKD}, \mathrm{CD} 4$ and $\mathrm{CD} 8+$ lymphocytes count) on the incidence of BSIs.

Incidence is reported as rate of events per 100 recipient-days and the hazard ratio (HR) is always reported with a $95 \%$ level of confidence. Two models have been fitted, one relative one relative to the first 30 days after transplantation and one from 31 from 365 days after transplant. The STATA 15 statistical package was used for all analyses.

\section{Results}

One-hundred-fifteen patients received a SOT during the study (77 in period 1 and 38 in period 2); their median age at the time of transplantation was 56 years (1-3 IQR: 49-60), 72 patients (66\%) were males. Of these, 73 (63.5\%) were heart recipients, and $42(36.5 \%)$ lung recipients, including both single as well as double lung transplant (Table 1).

Fifty-four BSI episodes were recorded in 41 patients (36.7\%) during the first year after transplantation, 9 patients had 2 or more BSI in this time period. The source of BSI was considered the central venous catheter in 21 episodes (39\%), the urinary tract in $12(22 \%)$, pneumonia in $17(31.5 \%)$ and $4(7.5 \%)$ were of unknown origin. 
Table 1. Epidemiological characteristics of patients

\begin{tabular}{|c|c|c|c|}
\hline & $\begin{array}{l}\text { Overall } \\
\text { N } 115\end{array}$ & $\begin{array}{c}\text { Heart transplant } \\
\times \mathbf{N 3}\end{array}$ & $\begin{array}{l}\text { Lung transplant } \\
\text { N } 42\end{array}$ \\
\hline Age & $55(47-60)$ & $55(48-60)$ & $57(49-60)$ \\
\hline $\begin{array}{l}\text { Gender } \\
\text { M } \\
\text { F }\end{array}$ & $\begin{array}{l}77 \\
38\end{array}$ & $\begin{array}{l}48 \\
25\end{array}$ & $\begin{array}{l}29 \\
13\end{array}$ \\
\hline $\begin{array}{l}\text { Period of study } \\
1 \\
2\end{array}$ & $\begin{array}{l}77 \\
38\end{array}$ & $\begin{array}{l}48 \\
34\end{array}$ & $\begin{array}{l}20 \\
13\end{array}$ \\
\hline $\begin{array}{l}\text { Cause of transplant } \\
\text { Dilatative cardiomiopathy } \\
\text { Acute myocardial infarction } \\
\text { Hypertrophic } \\
\text { restrictive cardiomyopathy } \\
\text { Emphysema } \\
\text { Fibrosis } \\
\alpha 1 \text { antitrypsin deficit } \\
\text { Pulmonary hypertension } \\
\text { Other }\end{array}$ & & $\begin{array}{c}52 \\
2 \\
18 \\
1\end{array}$ & $\begin{array}{c}7 \\
11 \\
6 \\
3 \\
6\end{array}$ \\
\hline CKD & 15 & 10 & 5 \\
\hline Diabetes & 5 & 3 & 2 \\
\hline CD4 cell count * & $502(292-749)$ & $442(164-621)$ & $634(418-868)$ \\
\hline CD8 cell count * & $294(118-438)$ & $188(110-354)$ & $436(233-608)$ \\
\hline Number of BSI & 64 & 37 & 17 \\
\hline $\begin{array}{l}\text { Source of BSI } \\
\text { CVC } \\
\text { Urinary tract } \\
\text { Pneumonia } \\
\text { unknown }\end{array}$ & $\begin{array}{c}21 \\
12 \\
17 \\
4\end{array}$ & $\begin{array}{c}12 \\
9 \\
8 \\
3\end{array}$ & $\begin{array}{l}9 \\
3 \\
9 \\
1\end{array}$ \\
\hline Colonization & 10 & 6 & 4 \\
\hline Deaths & 24 & 18 & 6 \\
\hline
\end{tabular}

*median (1-3 IQR)

Gram-negative bacteria were responsible for the majority of BSIs, more precisely, 34 Gram-negative bacteria were isolated (56\%) and were found to be mainly Enterobacterales. In 6 cases BSIs were polymicrobial. Table 2 describes the bacteria species as well as the mechanism of resistance by solid organ transplant type. Among Enterobacterales $81 \%$ were resistant to either to beta lactam-beta lactamase inhibitor or to carbapenems, among Stafilococci $87.5 \%$ were resistant to vancomicin.

Twenty-four patients died during the study timeframe (22\%) (type of SOT: 18 heart, 6 lung transplanted patients). Median time to death was 17 days (1-3 IQR 5-41 days). Four deaths were associated with a septic shock due to Gram-negative, all events occurred in period 1. Having a BSI was a risk factor for death (HR 5.2; 95\%CI 2.1-12-5, $\mathrm{p}<0.001)$.

BSIs in the first 30 days after transplant accounted for $48 \%$ of all events. Overall BSI incidence rate was 1.15 per 100 patient/days in the first 30 days after transplant; 1.49 per 100 patient/days in period 1 and 0.58 per 100 patient/days in period 2 (Figure 1). The use of broader antimicrobial prophylaxis was associated with reduced BSI in period 2 compared to period 1 (HR 0.39; 95\%CI 0.16-0.93, $\mathrm{p}=0.035$ ); CKD was associated with increased BSI risk (HR 2.45; 95\% CI 1.1-6, p=0.048). At multivariate analysis the risk of BSI still remained reduced in period 2 (HR 0.38; 95\%CI 0.14-1, p=0.05).

BSI incidence between 31 and 365 days after transplant was 0.15 per 100 patient/days, CKD and age were associated with BSI occurrence at univariate and while only age remained associated at multivariate analysis.

Rectal swab was positive for carbapenemase producing Klebsiella pneumonia in 2 cases, Citrobacter freundii VIM 1 positive in 1 case, Klebsiella pneumoniea/oxytoca ESBL in 2 cases, E coli ESBL in 3 cases, $E$ cloacae ESBL in 1 case. Targeted antimicrobial prophylaxis was administered in period 2 in colonized patients (Table 3). Rectal swab performed in the post-transplant period was positive for bacteria different from those isolated at transplant in 1 case (positive for vancomicin resistant Enterococcus faecium) (Table 4). After controlling for positive rectal swab, period 2 was associated with a decreased BSI risk compared with period 1 (HR 0.35; 95\%CI 0.13-0.9, $\mathrm{p}=0.03$ ).

\section{Discussion}

Bacterial infections have become the most frequent and challenging infections in SOT recipients $[2,13,14]$. Among bacterial infections, BSI are those associated with the highest mortality rates, which can reach $30 \%$ in heart transplant patients [15] and $25 \%$ in lung transplanted patients [16]. BSIs are more frequent in the first month after transplant, when, due to the fragility of the patients, the outcome may be fatal in roughly $36 \%$ of cases [17] in both lung and heart transplant [16,18]. In the present paper, we confirm that having a BSI in the post transplant was associated with increased death risk and that the causative agents were mainly represented by Gram negative bacteria (Enterobacterales in $30 \%$ of all isolates, followed by non fermenting bacteria). The use of broader antimicrobial prophylaxis at transplant was associated with reduction rate of BSI in the first month after transplant.

Table 2. Microbiological isolated in patients with BSI within the first year after transplant

\begin{tabular}{|c|c|c|c|c|}
\hline $\begin{array}{l}\text { Microbiological } \\
\text { isolated }\end{array}$ & $\begin{array}{l}\mathbf{N} \\
\mathbf{5 9}\end{array}$ & $\begin{array}{l}\text { Type of } \\
\text { resistence }\end{array}$ & Heart & Lung \\
\hline Gram positive & 16 & & & \\
\hline Staphylococcus aureus & 3 & $\begin{array}{l}\text { MS } \\
\text { MR }\end{array}$ & 2 & 1 \\
\hline Coagulase negative Staphylococcus & 9 & $\begin{array}{l}\text { MS } \\
\text { MR }\end{array}$ & $\begin{array}{l}1 \\
6\end{array}$ & 2 \\
\hline Enterococcus faecium & 2 & $\begin{array}{c}S \\
\text { VRE }\end{array}$ & $\begin{array}{l}1 \\
1\end{array}$ & \\
\hline Streptococcus oralis & 1 & & 1 & \\
\hline Granulicatellaadiacens & 1 & & 1 & \\
\hline Gram negative & 33 & & & \\
\hline $\begin{array}{l}\text { Klebsiella } \\
\text { pneumoniae }\end{array}$ & 12 & $\begin{array}{c}\text { S } \\
\text { KPC } \\
\text { ESBL }\end{array}$ & $\begin{array}{l}2 \\
3 \\
1\end{array}$ & $\begin{array}{l}3 \\
2 \\
1\end{array}$ \\
\hline Klebsiellaoxytoca & 2 & ESBL & 2 & \\
\hline Enterobacter cloacae & 2 & $\begin{array}{l}\text { MDR } \\
\text { ESBL }\end{array}$ & 1 & 1 \\
\hline Proteus mirabilis & 2 & ESBL & 2 & \\
\hline Escherichia coli & 4 & $\begin{array}{c}\mathrm{S} \\
\mathrm{ESBL}\end{array}$ & $\begin{array}{l}2 \\
2\end{array}$ & \\
\hline Pseudomonas aeruginosa & 6 & $\begin{array}{c}\text { S } \\
\text { ESBL } \\
\text { MDR }\end{array}$ & $\begin{array}{l}3 \\
1\end{array}$ & $\begin{array}{l}1 \\
1\end{array}$ \\
\hline $\begin{array}{l}\text { Stenotrophomonas } \\
\text { maltophilia }\end{array}$ & 2 & & 1 & 1 \\
\hline Serratia marcescens & 1 & & 1 & \\
\hline Hemophilus influenzae & 1 & & 1 & \\
\hline Hafni aalvei & 1 & & 1 & \\
\hline Raoultella ornithinolytica & 1 & & & 1 \\
\hline Anaerobies & 1 & & & \\
\hline Fusobacteriumnucleatum & 1 & & 1 & \\
\hline Fungi & 9 & & & \\
\hline Candida albicans & 2 & & 2 & \\
\hline Candida parapsilosis & 7 & & 4 & 3 \\
\hline
\end{tabular}


Table 3. Risk factors for bloodstream infections in solid organ transplant

\begin{tabular}{|c|c|c|c|c|c|c|c|c|c|c|c|c|}
\hline \multirow[b]{2}{*}{ Risk Factor } & \multicolumn{3}{|c|}{$\begin{array}{l}\text { Univariate analysis } \\
\text { Early events }\end{array}$} & \multicolumn{3}{|c|}{$\begin{array}{l}\text { Multivariable analysis } \\
\text { Early events }\end{array}$} & \multicolumn{3}{|c|}{$\begin{array}{c}\text { Univariate analysis } \\
\text { Late events }\end{array}$} & \multicolumn{3}{|c|}{$\begin{array}{l}\text { Multivariable analysis } \\
\text { Late events }\end{array}$} \\
\hline & HR & $95 \% \mathrm{Cl}$ & $\mathrm{p}$ & HR & $95 \% \mathrm{Cl}$ & $\mathrm{p}$ & HR & $95 \% \mathrm{Cl}$ & $\mathrm{p}$ & HR & $95 \% \mathrm{Cl}$ & $\mathrm{p}$ \\
\hline Age & 1.01 & $0.97-1.04$ & 0.6 & & & & 1.1 & $1-1.1$ & 0.05 & 1.1 & $1.01-1.1$ & 0.04 \\
\hline Gender & 1.1 & $0.5-2.5$ & 0.9 & & & & 0.7 & $0.3-1.5$ & 0.3 & & & \\
\hline Study period & 0.39 & $0.16-0.93$ & 0.035 & 0.38 & $0.14-1$ & 0.05 & 1.2 & $0.6-2.4$ & 0.5 & & & \\
\hline CD4 cell count & 0.99 & $0.09-1.01$ & 0.9 & & & & 1.1 & $0.99-1.1$ & 0.6 & & & \\
\hline CD8 cell count & 0.99 & $0.09-1.01$ & 0.8 & & & & 0.9 & $0.99-1.1$ & 0.4 & & & \\
\hline CKD & 2.5 & 1.1-6 & 0.05 & 1.8 & $0.7-4.6$ & 0.2 & 2.4 & $1.1-5.4$ & 0.03 & 2.3 & $0.8-6.7$ & 0.1 \\
\hline Diabetes & 2.7 & $0.8-8.9$ & 0.1 & & & & 2.1 & $0.5-8.5$ & 0.3 & & & \\
\hline
\end{tabular}

Table 4. List of colonized patients and targeted antimicrobial prophylaxis performed at transplant

\begin{tabular}{|c|c|c|c|c|}
\hline Bacteria isolated on rectal swab & Study period & BSI due to the same bacteria & Type of transplant & Antibiotic prophylaxis \\
\hline KPC & 1 & yes & Heart & Vancomicin \\
\hline E cloacae ESBL & 2 & no & Heart & Meropenem, vancomicin, \\
\hline E coli ESBL & 2 & no & Heart & Meropenem, vancomicin, \\
\hline E coli ESBL & 2 & no & Heart & Meropenem, vancomicin, \\
\hline K pneumonia ESBL/E coli ESBL & 2 & no & Heart & Meropenem, vancomicin, \\
\hline K oxytoca & 2 & no & Heart & Meropenem vancomicin, \\
\hline $\mathrm{KPC}$ & 1 & yes & Lung & Vancomicin \\
\hline E coli ESBL & 2 & no & Lung & Meropenem, vancomicin, \\
\hline Citrobacter VIM pos & 2 & no & Lung & Aztreonam + ceftazidime avibctam \\
\hline
\end{tabular}

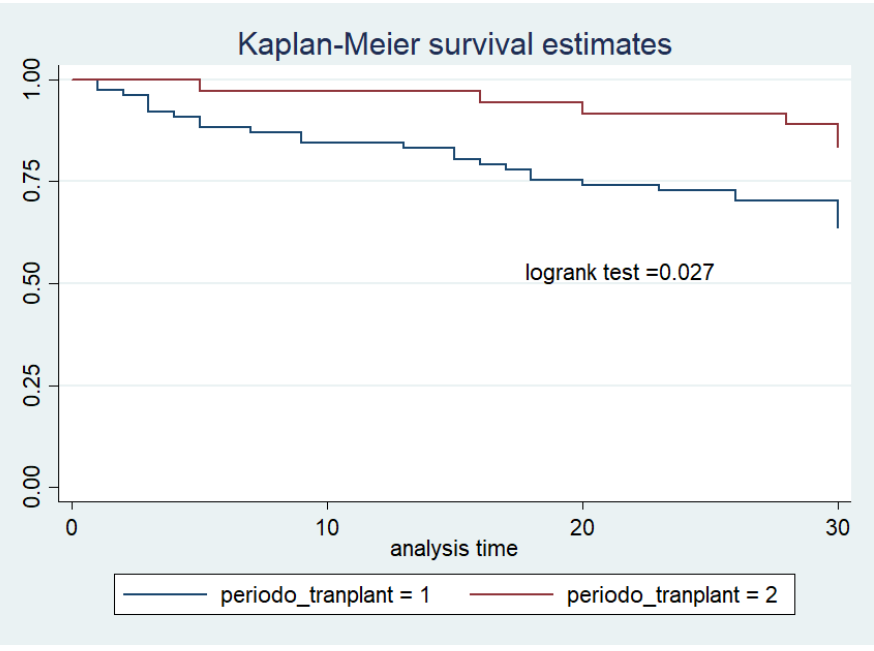

Figure 1. Kaplan-Meier curves showing cumulative probability of bloodstream infection in all SOT patients during the period 1 and period 2

A shift towards Gram-negative bacteria as the causative agents of BSI in SOT has recently been observed and nowadays Enterobacterales (which are part of Proteobacteria phylum) represent the leading cause of infection after SOT worldwide[14,19,20]. Enterobacterales are part of human intestinal microbiota where they are present in a variable amount, $<5 \%$ in the normal host [21] and with an increased percentage in the hospitalized colonized patient [22]. Immunocompromised adults with an alteration in the gut microbiota, with a percentage above $30 \%$ in the relative abundance of Proteobacteria, are exposed to an increased risk of developing a BSI [22]. Consistently, an abundance of carbapenemase producing Klebsiella pneumoniae in the intestinal microbiota has been associated with an increased risk of a subsequent bacteremia [23]. Approximately 50\% of BSIs occurred in the first month after transplant. Multiple factors as the translocation due to disruption in microperfusion and/or damage to the mucosal barrier represent a risk factor for BSI in the post-transplant period [10] therefore the role of the antimicrobial prophylaxis should be to prevent infections associated to altered gut permeability.
The issue of antimicrobial prophylaxix at transplant is matter of debate, despite guidelines proposing the use of cefazolin as the antibiotic of choice as transplant prophylaxis [24] most of the Centers choose different options. Vancomycin plus aztreonam for 48 hours post transplant [25], or vancomycin plus cefazolin (or aztreonam for allergic patients) [26] have been reported in heart transplanted patients. A recent survey performed in lung transplant Centers describes that most (>70\%) used antibiotics against Gram negative strains (piperacillin/ tazobactam, cefepime, ceftazidime or carbapenem), even if no previous bronchial colonization had occurred [27] in order to cover also bacteria with different mechanism of resistance. ESBL carriers are at risk for subsequent BSI due to the same bacteria, independently form organ transplant type $[28,29]$. The rational of a broader or targeted prophylaxix is to protect the patients when they are more susceptible to infections. A possible limitation of this strategy might be the selection of a different resistant strain. In our experience, rectal swabs performed in the post-transplant period until the patients were hospitalized did not show the acquisition of different colonization bacteria, except for a single patient who acquired a VRE in a context where VRE was endemic. There is no clear evidence outlining better treatment for colonized patients undergoing solid organ transplant. Other proposed solutions are decolonization with nonabsorbable drugs or pre-emptive treatment on the basis of known microbiological data or targeted antimicrobial prohylaxis [12,30] Evidence regarding decolonization with oral antibiotics are poor [12]. Early antimicrobial treatment for multidrug resistant bacterial infections has been proposed for fragile colonized patients if they present signs and/or symptoms of severe infections, and includes the empirical use of two active drugs to overcome the high mortality rate that is nonetheless associated with carbapenem resistant bacteria BSI [30].

Among other factors possibly associated to risk of BSI infection data on CD4+ and CD8+ cell count in SOT patients were evaluated. CD4+ and CD8+ cell count within one month from BSI occurrence were comparable with those of patients without BSIs. Low CD4+ or CD8 + cell count post transplant has been associated with increased frequency with viral infections [31] and higher mortality due to Pneumocystis jiroveci pneumonia [32]. The value of CD4+ and CD8+ cell count as 
a prognostic marker for BSIs instead is limited and this observation is consistent with BSIs not being considered as "opportunistic infections" but more a condition associated with classical risk factors such as gut barrier alteration early post transplant and age and CKD later.

The limitations of the present study are represented for the most part by its observational retrospective nature and by being a single center study with a small number of patients treated. With these limits a significant reduction in BSI incidence during the first month after transplant in patients who received a broader (or targeted) antimicrobial prophylaxis has been observed. Moreover a larger cohort of patients would be helpful in order to corroborate the results reported herein.

\section{Conclusions}

In the present paper we report the data on the antimicrobial results and outcomes of BSIs in heart and lung transplant patients in the first year after transplant. Broader antimicrobial prophylaxis at transplant is an option to reduce BSI incidence in the first month after transplant.

\section{Acknowledgments}

\section{Funding}

No funding or sponsorship was received for this study or publication of this article.

\section{Disclosure}

The authors report no conflicts of interest.

\section{Authors contribution}

Conceptualization, E.S, A.D.M, and R.B, investigation A.T, F.M, B.C, C.P, S.P, R.V; writing-original draft preparation, E.S and A.D.M; writing-review and editing, S.P, C.P, R.V; formal analisys, ADS, microbiology P.C. All authors have read and agreedto the published version of the manuscript.

\section{Compliance with ethics guidelines}

The study has been approved by local Ethical Review Board (prot 20180068992). The study was performed in accordance with the Helsinki Declaration of 1964, and its later amendments.

\section{References}

1. Dorschner P, McElroy LM, Ison MG (2014) Nosocomial infections within the first month of solid organ transplantation. Transpl Infect Dis 16: 171-187. [Crossref]

2. Shultes KC, Shuster JE, Micek S, Vader JM, Balsara K, et al. (2018) Outcomes and Predictors of Early Infection after Heart Transplantation. Surgical Infections 19: 516522. [Crossref]

3. Bodro M, Sabé N, Tubau F, Vader JM, Balsara K, Baliellas C, et al. (2013) Risk factors and outcomes of bacteremia caused by drug-resistant ESKAPE pathogens in solidorgan transplant recipients. Transplantation 96: 843-849. [Crossref]

4. Moreno A, Cervera C, Gavaldá J, Rovira M, Cámara R, et al. (2007) Bloodstream infections among transplant recipients: Results of a nationwide surveillance in Spain. Am J Transplant 7: 2579-2586. [Crossref]

5. Koller MT, Van Delden C, Müller NJ, Baumann P, Lovis C, et al. (2013) Design and methodology of the Swiss Transplant Cohort Study (STCS): A comprehensive prospective nationwide long-term follow-up cohort. Eur J Epidemiol 28: 347-355. [Crossref]

6. Cervera C, van Delden C, Gavaldà J, Welte T, Akova M, et al. (2014) Multidrugresistant bacteria in solid organ transplant recipients. Clin Microbiol Infect 20: 49-73. [Crossref]

7. Al-Hasan MN, Razonable RR, Eckel-Passow JE, Baddour LM (2009) Incidence rate and outcome of gram-negative bloodstream infection in solid organ transplant recipients. Am J Transplant 9: 835-843. [Crossref]
8. Taur Y, Pamer EG (2013) The intestinal microbiota and susceptibility to infection in immunocompromised patients. Curr Opin Infect Dis 26: 332-337. [Crossref]

9. Giannella M, Bartoletti M, Campoli C, et al. (2019) The impact of carbapenemaseproducing Enterobacteriaceae colonization on infection risk after liver transplantation a prospective observational cohort study. Clin Microbiol Infect 25: 1525-1531. [Crossref]

10. Alevizakos M, Kallias A, Flokas ME, Mylonakis E (2017) Colonization with extendedspectrum beta-lactamase-producing Enterobacteriaceae in solid organ transplantation A meta-analysis and review. Transpl Infect Dis 19: 1-6. [Crossref]

11. Aguado JM, Silva JT, Fernández-Ruiz M, Cordero E, Fortún J, et al. (2018) Management of multidrug resistant Gram-negative bacilli infections in solid organ transplant recipients: SET/GESITRA-SEIMC/REIPI recommendations. Transplant Rev 32: 36-57. [Crossref]

12. Tacconelli E, Mazzaferri F, de Smet AM, Bragantini D, Eggimann P, et al. (2019) ESCMID-EUCIC clinical guidelines on decolonization of multidrug-resistant Gramnegative bacteria carriers. Clin Microbiol Infect 25: 807-817. [Crossref]

13. Singh N, Paterson DL, Gayowski T, Wagener MM, Marino IR (2000) Predicting bacteremia and bacteremic mortality in liver transplant recipients. Liver Transpl 6: 5461. [Crossref]

14. Kritikos A, Manuel O (2016) Bloodstream infections after solid-organ transplantation. Virulence 7: 329-340. [Crossref]

15. Shao M, Wan Q, Xie W, Ye Q (2014) Bloodstream infections among solid organ transplant recipients: Epidemiology, microbiology, associated risk factors for morbility and mortality. Transplant Rev 28: 176-181. [Crossref]

16. Husain S, Chan KM, Palmer SM, Hadjiliadis D, Humar A, et al. (2006) Bacteremia in lung transplant recipients in the current era. Am J Transplant 6: 3000-3007. [Crossref]

17. Hsu RB, Chang CI, Fang CT, Chang SC, Wang SS, et al. (2011) Bloodstream infection in heart transplant recipients: 12-year experience at a university hospital in Taiwan. Eur J Cardiothorac Surg 40: 1362-1367. [Crossref]

18. Hsu R Bin, Chang CI, Fang CT, Chang SC, Wang SS, et al. (2011) Bloodstream infection in heart transplant recipients: 12-year experience at a university hospital in Taiwan. Eur J Cardiothorac Surg 40: 1362-1367. [Crossref]

19. Oriol I, Sabé N, Simonetti AF, Lladó L, Manonelles A, et al. (2017) Changing trends in the aetiology, treatment and outcomes of bloodstream infection occurring in the first year after solid organ transplantation: a single-centre prospective cohort study. Transpl Int 30: 903-913. [Crossref]

20. Lanini S, Costa AN, Puro V, Procaccio F, Grossi PA, et al. (2015) Incidence of carbapenem-resistant gram negatives in Italian transplant recipients: A nationwide surveillance study. PLOS ONE 10: 1-15. [Crossref]

21. Shin NR, Whon TW, Bae JW (2015) Proteobacteria: microbial signature of dysbiosis in gut microbiota. Trends Biotechnol 33: 496-503. [Crossref]

22. Taur Y, Xavier JB, Lipuma L, Ubeda C, Goldberg J, et al. (2012) Intestinal Domination and the Risk of Bacteremia in Patients Undergoing Allogeneic Hematopoietic Stem Cell Transplantation. Clin Infect Dis 55: 905-914. [Crossref]

23. Shimasaki T, Seekatz A, Bassis C, Rhee Y, Yelin RD, et al. (2019) Increased relative abundance of Klebsiella pneumoniae carbapenemase-producing Klebsiella pneumoniae within the gut microbiota is associated with risk of bloodstream infection in long-term acute care hospital patients. Clin Infect Dis 68: 2053-2059. [Crossref]

24. Bratzler DW, Dellinger EP, Olsen KM, Perl TM, Auwaerter PG, et al. (2013) Clinical practice guidelines for antimicrobial prophylaxis in surgery. Am J Health Syst Pharm 70: 195-283. [Crossref]

25. Oriol I, Sabé N, Simonetti AF, Lladó L, Manonelles A, et al. (2017) Changing trends in the aetiology, treatment and outcomes of bloodstream infection occurring in the first year after solid organ transplantation: a single-centre prospective cohort study. Transpl Int 30: 903-913. [Crossref]

26. Bhatt PJ, Ali M, Rana M (2020) Infections due to multidrug-resistant organisms following heart transplantation: Epidemiology, microbiology, and outcomes. Transplant Infectious Disease 22: 1-9.

27. Coiffard B, Prud'Homme E, Hraiech S (2020) Worldwide clinical practices in perioperative antibiotic therapy for lung transplantation. BMC pulmonary medicine 20 109 
28. Anesi JA, Lautenbach E, Tamma PD, Thom KA, Blumberg EA, et al. (2020) Risk Factors for Extended-Spectrum $\beta$-lactamase-Producing Enterobacterales Bloodstream Infection Among Solid-Organ Transplant Recipients. Clin Infect Dis 2020: ciaa190. [Crossref]

29. Shafiekhani M, Karimzadeh I, Nikeghbalian S, Firoozifar M, Pouladfar G, et al. (2020) Comparison of ceftizoxime plus ampicillin-sulbactam versus gentamicin plus ampicillin-sulbactam in the prevention of post-transplant early bacterial infections in liver transplant recipients: A randomized controlled trial. Infect Drug Resist 13: 89-98. [Crossref]
30. Cano A, Gutiérrez-Gutiérrez B, Machuca I, Gracia-Ahufinger I, Pérez-Nadales E, et al. (2018) Risks of Infection and Mortality among Patients Colonized with Klebsiella pneumoniae Carbapenemase-Producing K. pneumoniae: Validation of Scores and Proposal for Management. Clin Infect Dis 66: 1204-1210. [Crossref]

31. Calarota SA, Aberle JH, Puchhammer-Stöckl E, Baldanti F (2015) Approaches for monitoring of non virus-specific and virus-specific T-cell response in solid organ transplantation and their clinical applications. J Clin Virol 70: 109-119. [Crossref]

32. Freiwald T, Büttner S, Cheru NT (2020) CD4+ T cell lymphopenia predicts mortality from Pneumocystis pneumonia in kidney transplant patients. Clinical Transplantation 34: e13877.

Copyright: (C2021 Seminari E. This is an open-access article distributed under the terms of the Creative Commons Attribution License, which permits unrestricted use, distribution, and reproduction in any medium, provided the original author and source are credited. 